Dr. KUENSSBERG pointed out that collecting statistics was a highly specialized subject, and there were now four special units in Britain to do this. They were academic units, and not connected with the administrators, and therefore would be challenged by the administrators, who tended not to accept figures unless produced by themselves. The Government should be asked how far it had got with the remit which the Review Body clearly put on to the Government on at least two occasions, in the Fifth Report and the Seventh Report, when it said that there were not enough figures available. There was a medical audit in most countries which had medical care schemes, and in this country it was conspicuous by its absence, but it was not for the Association to carry this out.

\section{Ethics}

The Committee considered the following communication from the Central Ethical Committee :

"The attention of the Central Ethical Committee has been drawn to an entry in an executive council medical list indicating that certain general practitioners offered cervical cytology service at specified times. The Committee at its meeting on 25 October passed the following resolution :

'That the Central Ethical Committee strongly deplores the practice of special services being offered by general practitioners being publicized in the executive council list."

"It would be helpful for the Central Ethical Committee to know whether the General Medical Services Committee supports it in this view and if so would it consider making representations to any executive council which was known to include reference to such special services in its list of N.H.S. doctors.

"From a random check of executive council lists it appears to be the usual custom to indicate such services as maternity medical services, antenatal clinics, child welfare clinics, although there is no uniformity in the manner in which these services are indicated."

Dr. RIDGe said that each executive council was required to produce a list of doctors providing maternity medical services. Strictly speaking, the Committee should insist that the executive council produced one list of doctors offering general medical services and a separate list of doctors offering maternity medical services, because they were the subject of a separate contract. It had been agreed that those doctors who also offered maternity medical services would be included in the general list, and this was not to be considered as advertising.

Dr. JoAn Chappell explained that the reason for indicating that certain services were given at a certain time was for the benefit of the patient, so that people came at a regular time each week, especially if it was necessary to employ high-grade ancillary help at that time. The doctor did not want to be interrupted during that session by other members of the public coming into the surgery for minor complaints.

After a short discussion the Committee decided to send the matter back to the Ethical Committee with the recommendation that more inquiries should be made as to the practice throughout the country in giving this sort of information in executive council lists.

\section{Corrections}

Dr. Howie Wood asked that a statement attributed to him in the report of

the meeting of 5 January (21 January, p. 18) should be corrected. He wished to be recorded as saying that he was instructed by both his local medical committee and the executive council to oppose the regionalization of medical service committees at the Annual Conference of Representatives of Local Medical Committees.

In the report of the early part of this

meeting of the G.M.S. Committee (11 February, p. 45) under the heading "Subtle Change" Dr. Ridge was reported as saying : "It is this subtle change in the significance of the Review Body recommendation which we now find informally is not acceptable to the Ministry." This should have read "is acceptable."

\title{
Public Health Committee
}

A meeting of the Public Health Committee was held on 27 January. Dr. C. METCALFE BROWN was in the chair.

Members thought that a senior medical officer should be co-opted to the Committee. Dr. J. M. Dunlop proposed Dr. H. MacAnespie, and the Committee agreed to this proposal.

\section{Maternity Services Administration}

The executive subcommittee had considered the resolution passed at the A.R.M. 1966: "That the Representative Body is of the opinion that the present tripartite control of the maternity services should be replaced by a unified administration of a single service incorporating all the hospital and domiciliary element in closely integrated local groups." The Central Consultants and Specialists Committee and the General Medical Services Committee were also considering the matter.

The Public Health Committee agreed to the recommendation of its executive subcommittee that the C.C. and S. Committee should be informed that "integration of the maternity services is being effected in many areas already by Maternity Liaison Committees based on mutual confidence and understanding. In the Committee's view there is little that cannot be achieved at the present time given good will at local level."

\section{Attachment to General Practice}

In discussion of another A.R.M. (1966) resolution the Committee reiterated its support for the principle of attachment of nurses and health visitors to general practice. The Committee decided to recommend to the General Medical Services Committee that an approach should be made to the Minister of Health with a view to his encouraging local authorities to provide attachment facilities so far as is practicable, and in this connexion it should be pointed out to the Minister that attachment would be facilitated where practitioners worked in groups.

The recommendation was accepted.

\section{Area Health Boards}

The Committee considered the comments of the executive subcommittee on a report by the Subcommittee on Area Health Boards (Welsh Committee) and the suggested pilot area in Wales.
Dr. Dunlop asked how medical officers under area health boards would be paid.

Dr. J. D. J. Havard (Under Secretary) said that all doctors in the area of an area health board would be employed by the board. For example, the area health board would be responsible for the medical and ancillary staffing of the school health service and would act as the agent of the local education authority in implementing the policy of that authority. One of the board's consultants in social health would be designated as principal school medical officer by agreement with the local education authority to which he would be responsible.

Dr. J. Alun Evans said that there had been no support for area health boards in any of the committees he had attended. The Chairman, however, pointed out that the Committee did not have to say it approved the setting up of area health boards in England, but simply that it had no objections to Wales being used as a pilot area.

The Committee decided to inform the Welsh Committee that in so far as the suggested pilot area for area health boards is an experimental project and applies only to Wales it would, in general, have no objection to the suggestions put forward in the report.

\section{Cervical Cytology Service}

The Committee considered two A.R.M. resolutions (1966) concerning the cervical cytology service. These stated:

“(1) That, in view of current Ministerial policy on the establishment of a nation-wide cervical cytology service and the total in adequacy of present facilities, this Meeting instructs Council to press urgently for the provision of a substantial sum of money to be set aside for the sole purpose of achieving such a service. In addition adequate funds be provided as quickly as possible for the other cytological services being developed."

“(2) That the present knowledge of the natural history of carcinoma of the cervix is insufficient to permit the intervals between taking cervical smears and patients' age limits for this investigation to be fixed as in paragraph 229 of the Report of Council and paragraph 84 of the Third Report on the Family Doctor Service. Such directions are a real source of danger to patients and an interference with clinical freedom."

After discussion the Committee agreed to recommend to Council that facilities for cervical cytology, including laboratory facilities, should be extended, as this would facilitate both more frequent examinations and a lowering of the age at which it is recommended the examination should be carried out. 